University of Nebraska - Lincoln

DigitalCommons@University of Nebraska - Lincoln

US Department of Energy Publications

U.S. Department of Energy

2001

\title{
Distribution and Retention of 137Cs in Sediments at the Hanford Site, Washington
}

James Mckinley

Pacific Northwest National Laboratory, james.mckinley@pnl.gov

Cynthia Zeissler

National Institute for Standards and Technology

John M. Zachara

Pacific Northwest National Laboratory, john.zachara@pnl.gov

R. Jeffrey Serne

Pacific Northwest National Laboratory

Richard Lindstrom

National Institute for Standards and Technology

See next page for additional authors

Follow this and additional works at: https://digitalcommons.unl.edu/usdoepub

Part of the Bioresource and Agricultural Engineering Commons

Mckinley, James; Zeissler, Cynthia; Zachara, John M.; Serne, R. Jeffrey; Lindstrom, Richard; Schaef, Herbert; and Orr, Robert, "Distribution and Retention of 137Cs in Sediments at the Hanford Site, Washington" (2001). US Department of Energy Publications. 217.

https://digitalcommons.unl.edu/usdoepub/217

This Article is brought to you for free and open access by the U.S. Department of Energy at DigitalCommons@University of Nebraska - Lincoln. It has been accepted for inclusion in US Department of Energy Publications by an authorized administrator of DigitalCommons@University of Nebraska - Lincoln. 


\section{Authors}

James Mckinley, Cynthia Zeissler, John M. Zachara, R. Jeffrey Serne, Richard Lindstrom, Herbert Schaef, and Robert Orr 


\section{Distribution and Retention of ${ }^{137} \mathrm{Cs}$ in Sediments at the Hanford Site, Washington}

\author{
JAMES P. MCKINLEY,*,† \\ CYNTHIA J. ZEISSLER, \\ JOHN M. ZACHARA, ${ }^{\dagger}$ R. JEFFREY SERNE, ${ }^{\dagger}$ \\ RICHARD M. LINDSTROM, \\ HERBERT T. SCHAEF, † AND \\ ROBERT D. ORR ${ }^{\dagger}$
}

Pacific Northwest National Laboratory, Richland, Washington 99352, and National Institute for Standards and Technology, 100 Bureau Drive, Gaithersburg, Maryland 20899-8371

${ }^{137}$ Cesium and other contaminants have leaked from single-shell storage tanks (SSTs) into coarse-textured, relatively unweathered unconsolidated sediments. Contaminated sediments were retrieved from beneath a leaky SST to investigate the distribution of adsorbed ${ }^{137} \mathrm{CS}^{+}$ across different sediment size fractions. All fractions contained mica (biotite, muscovite, vermiculatized biotite), quartz, and plagioclase along with smectite and kaolinite in the clay-size fraction. A phosphor-plate autoradiograph method was used to identify particular sediment particles responsible for retaining ${ }^{137} \mathrm{Cs}^{+}$. The $\mathrm{Cs}$-bearing particles were found to be individual mica flakes or agglomerated smectite, mica, quartz, and plagioclase. Of these, only the micaceous component was capable of sorbing $\mathrm{Cs}^{+}$ strongly. Sorbed ${ }^{137} \mathrm{Cs}^{+}$could not be signific antly removed from sediments by leaching with dithionite citrate buffer or $\mathrm{KOH}$, but a fraction of the sorbed ${ }^{137} \mathrm{Cs}^{+}(5-22 \%)$ was desorbable with solutions containing an excess of $\mathrm{Rb}^{+}$. The small amount of ${ }^{137} \mathrm{Cs}^{+}$that might be mobilized by migrating fluids in the future would likely sorb to nearby micaceous clasts in downgradient sediments.

\section{Introduction}

The Hanford Site in eastern Washington is the subject of a vast remediation effort. Approximately $40 \mathrm{yr}$ of Pu production created large volumes of waste, some of which reside in sediments as environmental contaminants. ${ }^{137} \mathrm{C}$ s was a major component of the radioactive wastes. The chemical controls on the mobility of this nuclide and the strength with which it is bound in the subsurface have bearing on remediation activities at the site.

Much low-level waste was dumped directly to ground at the site, and most of the high-level waste was stored in 162 massive underground tanks, ranging in capacity from 210 to $4100 \mathrm{~m}^{3}$ (55 000-1.1 million gal). The chemically complex wastes had variable composition becauseat least six different reprocessing schemes were used to extract $\mathrm{Pu}$ and recover other elements such as $U$. A common feature was a high concentration of $\mathrm{NaNO}_{3} / \mathrm{NO}_{2}$ salts $(>0.5 \mathrm{~mol} / \mathrm{L})$. Approximately $40 \%$ of the tanks' total radioactivity originated from

\footnotetext{
*Corresponding author e-mail: james.mckinley@pnl.gov; phone: (509)375-6841; fax: (509)375-6954.

+ Pacific Northwest National Laboratory.

₹ National Institute for Standards and Technology.
}

${ }^{137} \mathrm{Cs}$, which is highly soluble and found in the liquid supernate at activities ranging up to $2 \times 10^{10} \mathrm{~Bq} / \mathrm{L}(0.5 \mathrm{Ci} / \mathrm{L}=0.000041$ $\mathrm{mol}{ }^{137} \mathrm{Cs} / \mathrm{L}$ ), with many tanks falling in the range of $0.4-1.5$ $\times 10^{10} \mathrm{~Bq} / \mathrm{L}$.

Sixty-seven of the tanks are known to have leaked, discharging over $3800 \mathrm{~m}^{3}$ (> 1 million gal) of supernate and approximately $4 \times 10^{16} \mathrm{~Bq}$ (1 million $\mathrm{Ci}$ ) of ${ }^{137} \mathrm{Cs}^{+}$to the vadose zone. The directly measured activity from contaminated sediments has been as high as $10^{5} \mathrm{~Bq} / \mathrm{g}\left(10^{7} \mathrm{pCi} / \mathrm{g}\right)$, and indirect field estimates were as high as $10^{8} \mathrm{~Bq} / \mathrm{g}\left(10^{10}\right.$ $\mathrm{pCi} / \mathrm{g}$ ). Coarse-textured, micaceous sediments that make up the regional surface deposits $(1,2)$ have to a large degree sorbed the ${ }^{137} \mathrm{Cs}^{+}$, limiting vertical migration to distances of approximately $6-20 \mathrm{~m}(20-65 \mathrm{ft})$, but in some places ${ }^{137} \mathrm{Cs}^{+}$ has experienced little chemical retardation and has migrated more deeply. The chemical nature and reversibility of the sorption process are uncertain, and concern has focused on whether ${ }^{137} \mathrm{Cs}^{+}$will migrate over time to groundwater approximately $30-40 \mathrm{~m}$ (100-130 ft) below the tanks.

To usefully determine the potential for the future mobilization and transport of ${ }^{137} \mathrm{Cs}^{+}$in vadosesediments, several unanswered questions must beaddressed. First, how strongly is ${ }^{137} \mathrm{Cs}^{+}$bound to thecontaminated sediments? Second, with which mineral components is ${ }^{137} \mathrm{Cs}^{+}$associated? Third, are there differences in the strength of binding to different mineral components so that the quantity of ${ }^{137} \mathrm{Cs}^{+}$present in a given location affects mobility? The third question is key. If ${ }^{137} \mathrm{Cs}^{+}$is abundantly present, it may have saturated highly selective sorption sites and may also be present on low-affinity sites. The latter association would represent ${ }^{137} \mathrm{Cs}^{+}$ that could readily desorb and migrate with the desorbing fluid.

$\mathrm{Cs}^{+}$forms no sparingly soluble solid phases that could limit its aqueous concentration (e.g., ref 3). Retardation of $\mathrm{Cs}^{+}$movement in groundwater is therefore controlled by sorption, and $\mathrm{Cs}^{+}$is preferentially sorbed by phyllosilicate minerals, which include expansible layer silicates such as smectite and vermiculite and nonexpansible micas such as biotite and muscovite.

Theretention of $\mathrm{Cs}^{+}$by sediments and phyllosilicates has been intensively studied since anthropogenic ${ }^{137} \mathrm{Cs}^{+}$became a concern for environmental and health reasons (4-9). Sorption and desorption were observed to proceed in two steps: rapid initial reaction followed by slower continued reaction (or even renewed sorption, in thecase of desorption). This behavior was explained by the hypothetical interaction with three different chemical surface sites: (i) nonselective (fixed charge) exchange sites on phyllosilicate surfaces; (ii) selective frayed edge sites (FES) on micas, formed by the removal of $\mathrm{K}^{+}$from the phyllosilicate interlayers; and (iii) interlayer sites in micas, populated by the diffusion of ${ }^{137} \mathrm{Cs}$ from FES. (The transition from weathered vermiculitic 1.4$\mathrm{nm}$ spacing to unweathered 1.0-nm spacing on micas edgesthe FES - was hypothesized to form a favorable steric environment for the strong binding of dehydrated cations, e.g., $\mathrm{K}^{+}, \mathrm{Cs}^{+}, \mathrm{NH}_{4}^{+}$.) Sorption behavior could be linked to specific exchange sites as follows. Nonselective exchange sites weakly retained ${ }^{137} \mathrm{Cs}^{+}$, which could be readily and rapidly desorbed. The FES sites rapidly and energetically retained $\mathrm{Cs}^{+}$and also slowly desorbed $\mathrm{Cs}^{+}$, depending on system chemistry, explaining the slow sorption/ desorption step $(4,6)$. In most experimental studies, complete recovery of sorbed $\mathrm{Cs}^{+}$was not achievable, and this unrecovered $\mathrm{Cs}^{+}$ was considered to be "irreversibly sorbed" or "fixed". Fixed $\mathrm{CS}^{+}$was bound to FES or interlayer sites or both (6). More 


\section{SX Tank Farm \\ Central Hanford}

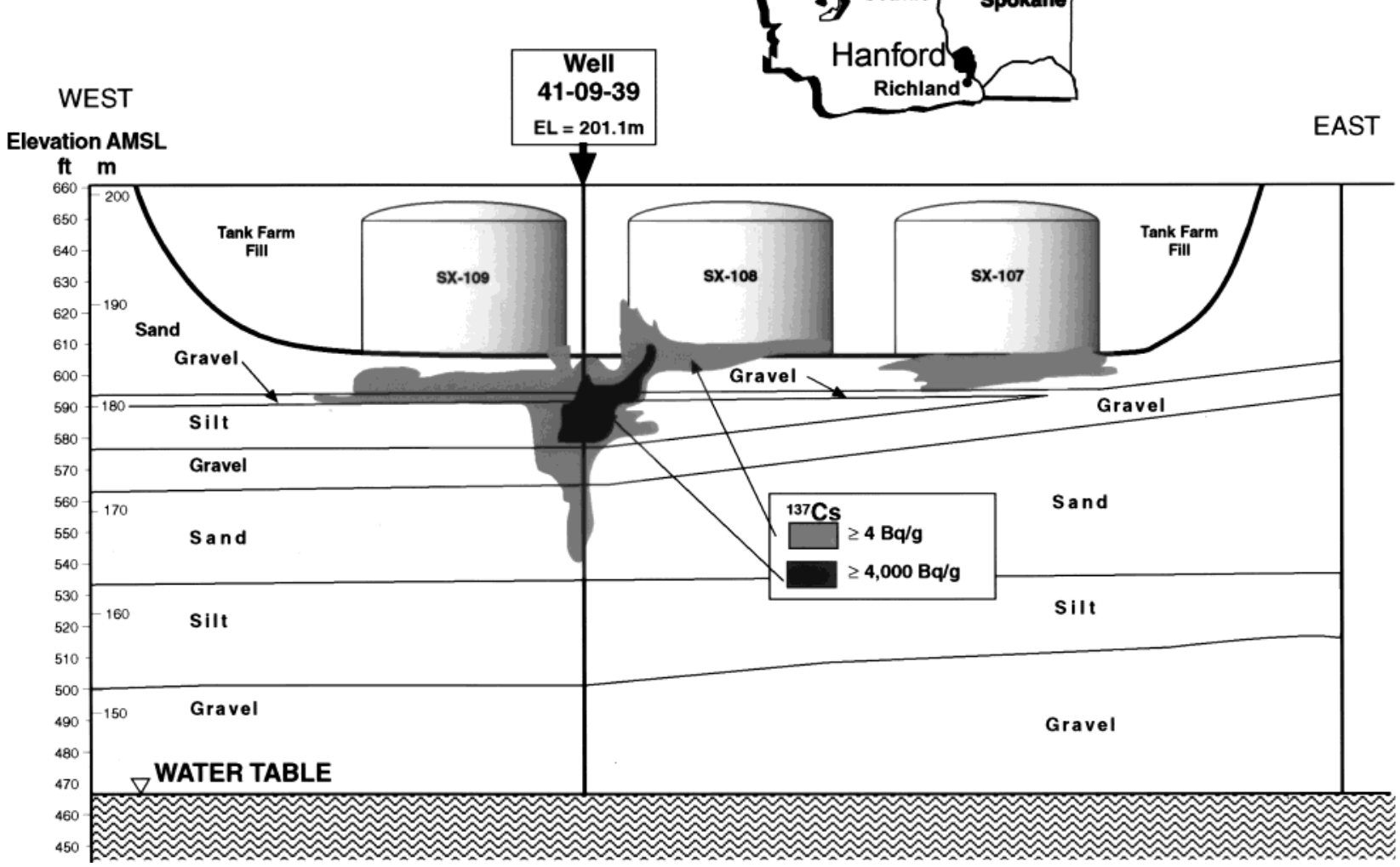

FIGURE 1. Vertical cross section of the SX Tank Farm at Hanford, show ing the extent and concentration of ${ }^{137} \mathrm{Cs}$ in contaminated sediments impacted by tank leakage. Well 41-09-39 was constructed to sample the contaminant plume.

recent field data, however, indicated significant desorption of $\mathrm{Cs}^{+}$, particularly by $\mathrm{NH}_{4}{ }^{+}$, over long periods $(5,10)$.

Theidea that some $\mathrm{Cs}^{+}$was fixed and unrecoverable may be erroneous. The replacement of $\mathrm{Cs}^{+}$sorbed to a mineral surface or to interlayer space is controlled by ion-exchange equilibria and is thereforethermodynamically reversible (4). The extent of $\mathrm{Cs}^{+}$diffusion into interlayer space would probably amount to less than $1 \mathrm{~nm} / \mathrm{yr}$ (8), so it may be that $\mathrm{Cs}^{+}$could not penetrate the bulk interlayers at all and was confined to exchange with $\mathrm{K}^{+}$on sites at the weathered edge of mica flakes (the FES) (4). This suggests that, on the crystal edge, proximal to the transition from 1.0 to $1.4 \mathrm{~nm}$ basal spacing, two strongsorption reactions could occur: $\mathrm{Cs}^{+}$might bind to sites where $\mathrm{K}^{+}$has been removed by weathering, or it might exchange with $\mathrm{K}^{+}$that is just in interlayer space. To better understand the limits on $\mathrm{Cs}^{+}$mobility and its future mobilization potential in Hanford sediments, we examined a restricted set of core samples removed from a ${ }^{137} \mathrm{Cs}-$ contaminated zone beneath a leaky SST and characterized the degree of ${ }^{137} \mathrm{Cs}^{+}$fixation and its mineral associations.

\section{Materials and Methods}

${ }^{137} \mathrm{CS}^{+}$contaminated core samples were obtained from the S-SX Tank Farm at Hanford (Figure 1). The farm contains 30 tanks, including SX-108, which was shown by spectral $\gamma$-logging to have leaked and distributed ${ }^{137} \mathrm{Cs}^{+}$to the vadose zone to a depth of about $37 \mathrm{~m}$ ( $120 \mathrm{ft}$ ), with maximum ${ }^{137} \mathrm{Cs}$ activities of $>4 \times 10^{3} \mathrm{~Bq} / \mathrm{g}(>100000 \mathrm{pCi} / \mathrm{g})$. Thetank wastes had $[\mathrm{OH}]_{\text {tot }}>5 \mathrm{~mol} / \mathrm{L}$ and $\mathrm{Al}(\mathrm{OH})_{4}{ }^{-}>1 \mathrm{~mol} / \mathrm{L}$. The leak occurred approximately $30 \mathrm{yr}$ ago, ca. 1 half-life for ${ }^{137} \mathrm{Cs}$. Samples were obtained by cable-tool drilling through the bottom of a dry well (designated 41-09-39) that had been

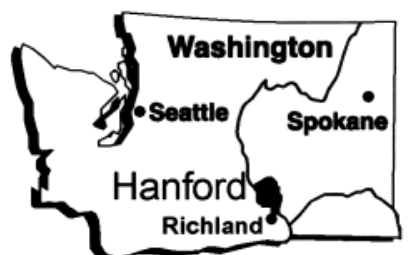

AST

\begin{tabular}{|c|c|c|c|c|c|}
\hline \multirow[b]{2}{*}{ sieve size } & & \multicolumn{4}{|c|}{$\begin{array}{c}\text { depth }(m), \\
\text { sample, moisture }\end{array}$} \\
\hline & & $\begin{array}{l}40.6, \\
2 C / D, \\
18.99\end{array}$ & $\begin{array}{c}40.9 \\
2 A / B \\
11.15\end{array}$ & $\begin{array}{c}\text { 41.21, } \\
3 A / B \\
9.47\end{array}$ & $\begin{array}{c}46.91 \\
12 \mathrm{~A} / \mathrm{B} \\
5.12\end{array}$ \\
\hline & $>2 \mathrm{~mm}$ & 2.15 & 0.90 & 0.36 & - \\
\hline very coarse sand & $2-1 \mathrm{~mm}$ & 2.58 & 0.90 & 0.97 & - \\
\hline coarse sand & $1-0.5 \mathrm{~mm}$ & 3.48 & 0.67 & 1.65 & - \\
\hline medium sand & $0.5-0.25 \mathrm{~mm}$ & 1.92 & 0.63 & 0.68 & - \\
\hline fine sand & $0.25-0.106 \mathrm{~mm}$ & 12.77 & 8.79 & 8.64 & - \\
\hline very fine sand & $0.106-0.053 \mathrm{~mm}$ & 27.98 & 37.03 & 30.62 & - \\
\hline silt and clay & $<0.053 \mathrm{~mm}$ & 47.91 & 49.61 & 56.16 & - \\
\hline total & & 98.79 & 97.83 & 99.07 & \\
\hline
\end{tabular}

a Moisture content in wt \%. Sediments were wet-sieved, and wt \% results (dry wt basis) represent post-sieving fractions of the original bulksediment. Totals less than $100 \%$ represent losses during processing. ${ }_{b}$ Values not determined are indicated by - .

constructed to log the contaminant plume and by coring through the underlying sediments to the water table at a depth of $64.4 \mathrm{~m}$. Continuous cores were removed over the interval from 40 to $49 \mathrm{~m}$, and intermittent samples were collected below that depth. The samples were numbered in sequence with depth and also given arbitrary letter suffixes (Tables 1-3).

The particlesize distributions of compositesamples were determined using a standard procedure (11). Moisture contents were determined gravimetrically. The size distributions of samples, in weight percents, were determined after wet sieving and drying among the size fractions: gravel $(>2$ $\mathrm{mm})$, very coarse sand (1-2 mm), coarse sand $(0.5-1 \mathrm{~mm})$, 
TABLE 2. $\gamma$-Counting Results for ${ }^{137} \mathrm{Cs}\left(\mathrm{Bq} \mathrm{g} \mathrm{g}^{-1}\right)$ as a Function of Sediment Size Fractions (dry wt basis)

\begin{tabular}{|c|c|c|c|c|c|}
\hline \multirow[b]{2}{*}{ sieve size } & & \multicolumn{4}{|c|}{ sample } \\
\hline & & $2 C / 2 D$ & $2 A / 2 B$ & $3 A / 3 B$ & $12 \mathrm{~A} / 12 \mathrm{~B}$ \\
\hline & $>2 \mathrm{~mm}$ & 2301 & 1909 & 1006 & $<1$ \\
\hline very coarse sand & $2-1 \mathrm{~mm}$ & 2516 & 2608 & 1002 & 5 \\
\hline coarse sand & $1-0.5 \mathrm{~mm}$ & 1898 & 2268 & 821 & 4 \\
\hline medium sand & $0.5-0.25 \mathrm{~mm}$ & 2671 & 1391 & 734 & 4 \\
\hline fine sand & $0.25-0.106 \mathrm{~mm}$ & 296 & 45 & 41 & 3 \\
\hline very fine sand & $0.106-0.053 \mathrm{~mm}$ & 396 & 7 & 21 & 1 \\
\hline silt and clay & $<0.053 \mathrm{~mm}$ & 584 & 42 & 322 & 10 \\
\hline
\end{tabular}
TABLE 3. Sediment Activities $\left(\mathrm{Bq}^{-1}\right)$ Calculated from Tables
1 and 2 and Measured Directly

$\begin{array}{lcccc} & \text { 2C/2D } & \text { 2A/2B } & \text { 3A/3B } & \text { 12A/12B } \\ \text { measured } & 1263 & 48 & 144 & 3 \\ \text { calculated } & 1152 & 94 & 225 & - \\ \text { a Values not determined are indciated by }- \text {. }\end{array}$

medium sand $(250-500 \mu \mathrm{m})$, fine sand $(106-250 \mu \mathrm{m})$, very fine sand $(53-106 \mu \mathrm{m})$, and silt plus clay $(<53 \mu \mathrm{m})$.

Subsamples from each core were placed in containers having precalibrated geometries for $\gamma$-energy analysis and were analyzed using 60\% efficient intrinsic germanium $\gamma$-detectors (Oxford Instruments, Inc.), calibrated against a commercial standard (QCY48A mixed $\gamma$; Amersham, Inc). Deadtime was kept below $1 \%$. Data quality was maintained using controls with peaks spanning the full detector range, monitored for peak position, counting rate, and intensity.

Random powder mountsfor X-ray diffraction (XRD) were prepared by crushing and were analyzed on a Phillips diffractometer (model 3520) using $\mathrm{Co} \mathrm{K} \alpha$ radiation. A separate, oriented clay-mineral mount from the $<53-\mu \mathrm{m}$ fraction was prepared by sedimentation of the $<2-\mu \mathrm{m}$ portion. Operating conditions were $40 \mathrm{keV}, 40 \mathrm{~mA}$ for the anode, with the goniometer scanning at $2 \mathrm{~s} / 0.05^{\circ} 2 \theta$ step from $5^{\circ}$ to $75^{\circ}$ $2 \theta$.

We conducted experiments to determine whether the desorbable quantity of ${ }^{137} \mathrm{Cs}^{+}$could be increased by chemical pretreatment to remove secondary minerals that could "armor" sorption sites. In each case, $1.5 \mathrm{~g}$ of sediment was reacted with the pretreating reagent, and the slurry was centrifuged, decanted, and washed with $20 \mathrm{~mL}$ of deionized water by shaking for $2 \mathrm{~h}$ and then centrifuged and decanted again. The wet sediment was reserved for desorption experiments. The reactant solution and wash water were radiocounted. ICP-MS measurements of $\mathrm{Fe}^{2+}$ were made to calculatetheamounts removed per gram of reacted sediment. A parallel procedure was done in which $5 \mathrm{~g}$ of sediment was treated, washed, and radiocounted for mass balance calculations.

Four chemical treatments were used to target different sediment qualities that could affect the sorption and retention of ${ }^{137} \mathrm{Cs}^{+}$. (i) Sodium dithionite was used to remove total free iron oxide (12). Sediment was reacted with $40 \mathrm{~mL}$ of $0.3 \mathrm{M}$ sodium citrate and slowly heated to $80^{\circ} \mathrm{C}$ in a water bath, then $0.5 \mathrm{~g}$ of sodium dithionite was added, and the mixture was stirred for $5 \mathrm{~min}$. A second $0.5 \mathrm{~g}$ of sodium dithionite was added, and the mixture wasstirred for $10 \mathrm{~min}$. (ii) Tamm's reagent was used to remove amorphous iron oxide (12). Sediment and $30 \mathrm{~mL}$ of $1 \mathrm{M}$ ammonium acetate, adjusted to $\mathrm{pH}$ 5.5, were added to separate $50-\mathrm{mL}$ centrifugetubes. After the solution was mixed for $1 \mathrm{~h}$, the $\mathrm{pH}$ was adjusted to 5.5; the tubes were centrifuged and decanted; and $30 \mathrm{~mL}$ of 0.175 $\mathrm{M}$ ammonium oxalate/ $0.1 \mathrm{M}$ oxalic acid solution, adjusted to $\mathrm{pH}$ 3.0, was added. The centrifuge tubes were wrapped with aluminum foil and shaken for $2 \mathrm{~h}$. (iii) Potassium hydroxidewas used to removeamorphous aluminum oxides (13). Sediment was mixed with $10 \mathrm{~mL}$ of $4 \mathrm{M}$ potassium hydroxide and shaken for $10 \mathrm{~min}$, and $100 \mathrm{~mL}$ of deionized water and 5 drops of $0.5 \%$ phenolphthalein were added to each flask. A total of $4 \mathrm{M} \mathrm{HCl}$ was added until each solution was colorless. (iv) Nitric acid was used as a harsh extractant/ desorber. Sediment was reacted with $10 \mathrm{~mL}$ of $2 \mathrm{M}$ nitric acid and stirred for $24 \mathrm{~h}$.

Rubidium ( $\left.0.1 \mathrm{M} \mathrm{RbNO}_{3}\right)$, for which micas havean affinity similar to that for $\mathrm{Cs}^{+}(14,15)$, was used to inducedesorption. (Since nitric acid is a strong desorber, the samples treated with nitric acid were not extracted with $\mathrm{Rb}^{+}$.) The wet equivalent of $0.40 \mathrm{~g}$ dry weight of sediment was transferred to centrifuge tubes, in triplicate, and suspended in $50 \mathrm{~mL}$ of $0.1 \mathrm{M} \mathrm{RbNO}_{3}$ solution. The tubes were shaken in duplicate sets for 1 and 29 days and then centrifuged, and the supernatant was counted for ${ }^{137} \mathrm{Cs}$.

Autoradiography, used previously in environmental studies of radioactive particles $(16,17)$, was used to identify ${ }^{137} \mathrm{Cs}^{+}$containing mineral particles and to quantify their activity levels. The particles were disseminated onto glass slides and exposed for 4320 min using a $20 \mathrm{~cm} \times 25 \mathrm{~cm}$ Fujifilm BAS-TR 2025 phosphor-plate, which was scanned with a Fuji BAS5000 digital autoradiography instrument at a $25-\mu \mathrm{m}$ pixel setting. The distribution of radioactivity on each was imaged, and grains were designated as "positive" or "negative" based on their ability to generate a radioactivity spot on the image. Secondary slides of segregated positive and negative grains were again imaged to confirm that grains of each designation were correctly identified. In addition, micas identified as biotite, vermiculite, or muscovite from the 56-105- and 105$250-\mu \mathrm{m}$ size fractions were affixed to slides in sets of sixeach (36 flakes total) for autoradiographic analysis without prior screening, and 24 micas were mounted (one per slide) for quantitative analysis. For quantitation, the pixel intensities associated with each grain were integrated. Background radiation intensities were measured from blank slides, and the mean of the background was subtracted from each grain area value to yield a background-subtracted intensity for each grain. This value was expressed in photostimulated luminescence (PSL) units, characteristic for this technique, which is linear with dose rate $(18,19)$. Uncertainties were evaluated using the standard deviation of the mean of the background counts (20). $\gamma$-Spectrometry results (methods described below) were regressed against the bulk phosphor measurements, producing an indirect calibration curve (21). Thelinear regression between theactivity and PSL units (valid over several orders of magnitude of activity) was used to estimate the activity of particles that had not been counted by $\gamma$-spectrometry, within the uncertainty determined by the regression.

Theseparated particles wereindividually assayed for ${ }^{137} \mathrm{Cs}^{+}$ with a low-background $\gamma$-ray spectrometer (22) nominally for $24 \mathrm{~h}$. The efficiency was calibrated for this geometry against a point-source Standard Reference Material (SRM 4215B). A 10-day background measurement with a blank slide showed no detectable ${ }^{137} \mathrm{Cs}$. Potassium-40 in the slides 


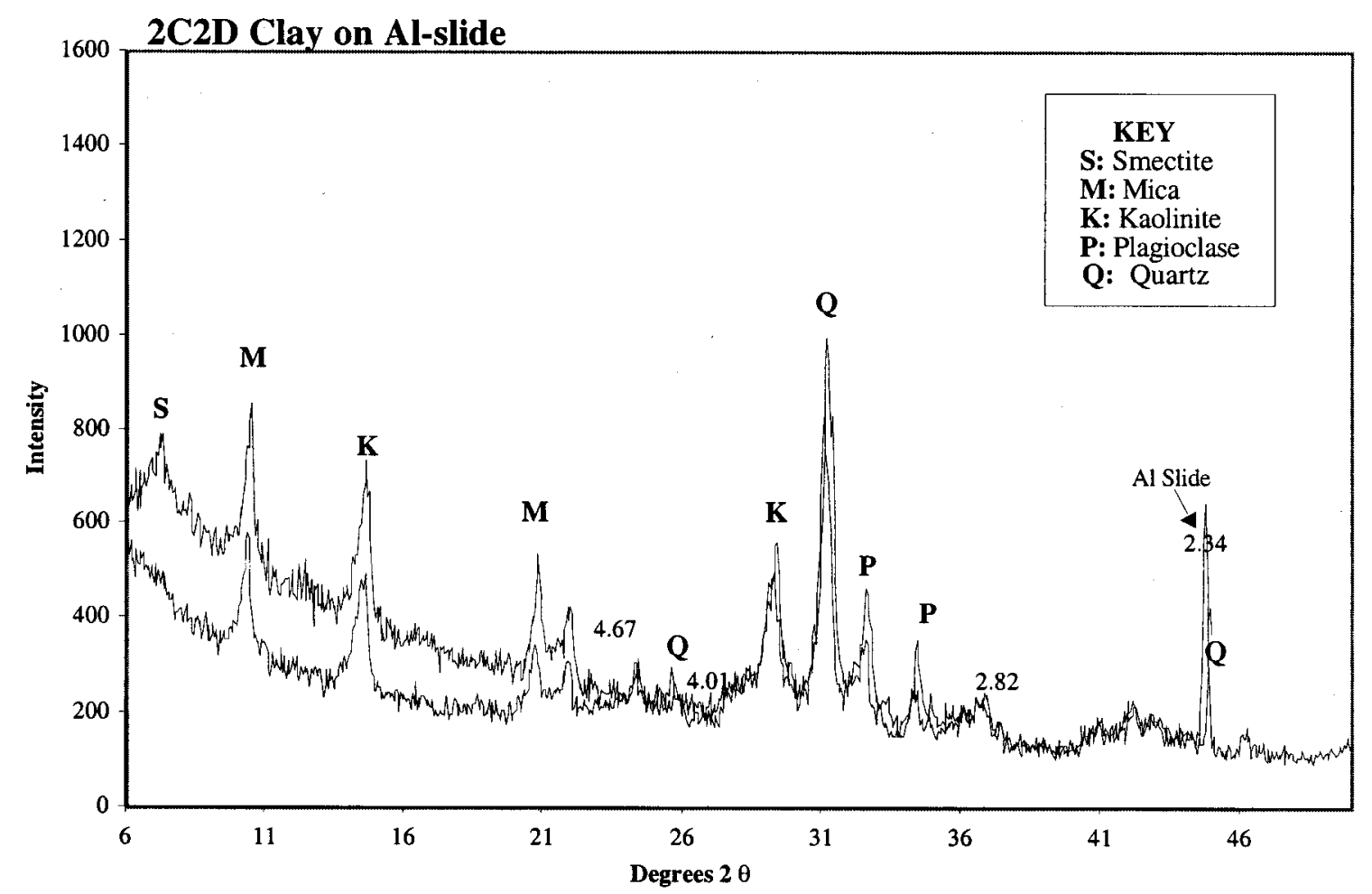

FIGURE 2. X-ray diffraction results from the clay-sized fraction $(<2 \mu \mathrm{m})$ of sample $2 C / D$ from well $41-09-39$. Upper line, Mg saturated; low er line, ethylene glycol saturated.

was monitored as a measure of the system's stability; the potassium counting rate was the same for all samples within statistics. The ${ }^{137} \mathrm{Cs}$ region of the spectrum was integrated with a fixed-boundary algorithm (23). Error estimates were computed according to standard methods (24).

For phase identification, sampleswereexamined optically using a CCD-equipped Leitz 2000 petrographic microscope and a JEOL JXA-8600 electron microprobe. Optical images were used as maps to examine the qualitative elemental compositions of individual grains, and the compositional information obtained by energy dispersive spectrometry was combined with noted optical properties to identify common rock-formingminerals. For example, a dark grain with distinct platy morphology including $\mathrm{Fe}$ and $\mathrm{K}$ was unambiguously biotite, and an equant grain composed of $\mathrm{Si}$ and $\mathrm{O}$ was identified as quartz. In the case of ${ }^{137}$ Cs-bearing grains, mineral composites were dissected during optical examination.

\section{Results and Discussion}

Sediment Characterization. For detailed study, we focused on samples from depths of 40.60-41.21 m (133-135ft). Bulksediment $\gamma$-counting (Table 3 ) showed that this interval had markedly elevated radioactivity relative to deeper, apparently less contaminated sediments. The uppermost sample (2C/ D) contained the most ${ }^{137} \mathrm{Cs}$ (activity of $1263 \mathrm{~Bq} \mathrm{~g}^{-1}$ ), and ${ }^{137} \mathrm{Cs}$ activity differed by a factor of over 400 between contaminated and uncontaminated sediments.

Fractional size analysis by sieving (Table 1), showed the sediments to consist predominantly (more than $75 \%$ of the total mass) of materials less than $106 \mu \mathrm{m}$ in diameter. Moisturecontents decreased from ca. 20 wt \% in 2C/ D to ca. $5 \mathrm{wt}$ \% in 12A/B. Water used during drilling through the original base of the well casing may have contributed to elevated moisture in the upper samples; 5 wt \% moisture is typical of Hanford vadose sediments (25). Examination of the subsamples revealed that some sediment clasts had aggregated into fragments composed of clay-sized and larger material and that fragments could be larger than the largest size passablethrough the overlyingsieve. Individual mineral components of these aggregates, however, weresmaller than the allowable upper diameter: large clasts did not pass through small sieve openings. Also, clay-size material was present in larger fractions ( $>53 \mu \mathrm{m}$ ) because rinsing during sieving did not remove all silt and clay-sized material.

After sieving and drying, individual size fractions were counted for ${ }^{137} \mathrm{C}$ s activity (Table 2). For comparison with the bulk measurements (Table 3 ), the total activity of each sediment was calculated from the weight percent and sizefraction activity values. For sample2C/D, thecalculated value was within $10 \%$ of the bulk value; for sample $2 A / B$, where the bulk activity was much lower, ca. $4 \%$ of the activity for $2 C / D$, theagreement was within a factor of 2 . In the upper sediments $(2 \mathrm{C} / \mathrm{D}, 2 \mathrm{~A} / \mathrm{B}$, and $3 \mathrm{~A} / \mathrm{B})$, the coarser fractions had the highest ${ }^{137} \mathrm{Cs}$ activity per unit mass. The relationship between grain sizeand mass-normalized activity suggested that thecoarser fractions could contain a large portion of the sorbed ${ }^{137} \mathrm{Cs}$, but because the coarser sizes constituted only a minor mass fraction of the sediments, the largest part of the total ${ }^{137} \mathrm{Cs}$ activity was contained in the silt and clay material.

Optical examination of the sediments showed discrete, large mica flakes in the coarser sediments $(0.25 \mathrm{~mm}$ and larger). In finer sediments, micas were present individually and as a component of aggregates. The micas could be operationally identified based on texture and color as biotite (black), muscovite (clear and most abundant), and vermiculite (rust and least abundant). XRD of individual sieve sizes (data not shown) indicated the presence only of quartz, plagioclase, and mica (undifferentiated) in all size fractions. Analysis of the clay-size fraction (Figure 2) indicated the presence of kaolinite, quartz, plagioclase, smectite, and mica fragments.

Theactivity measurements and petrographic observations were consistent with the preferential binding of ${ }^{137} \mathrm{Cs}^{+}$by nonexpansible phyllosilicates, particularly micas $(7,9,26)$. Since $\mathrm{Cs}^{+}$is less selectively bound by smectite and kaolinite, 


\section{A. Negative Grains}

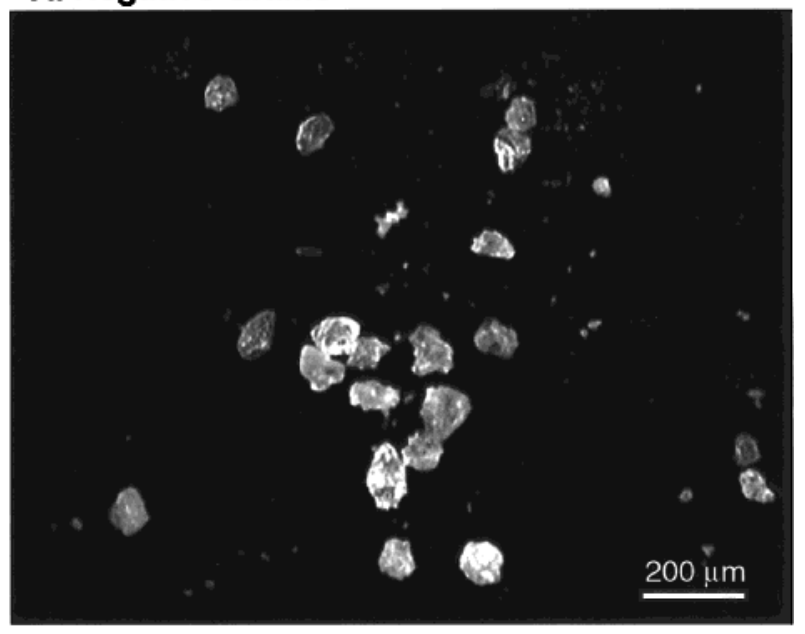

\section{B. Positive Grains}

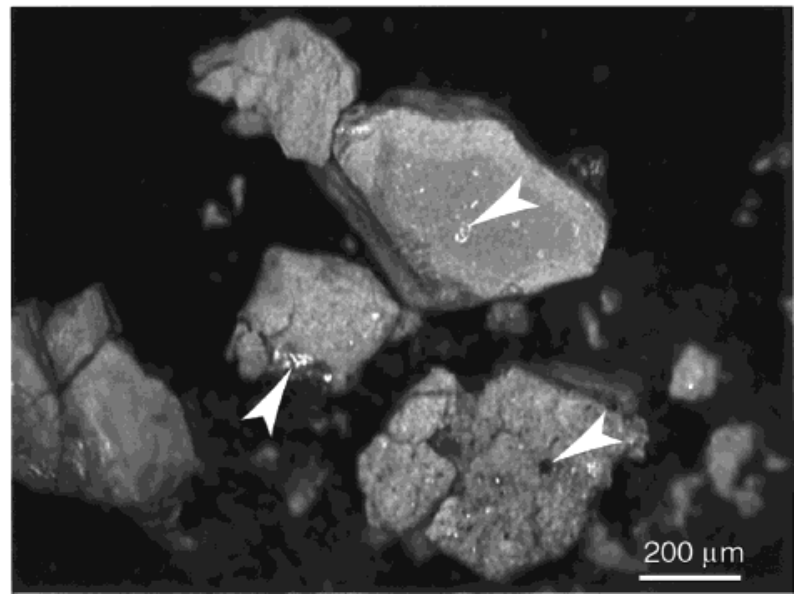

FIGURE 3. Photomic rographs of representative grains from the 53106- $\mu \mathrm{m}$ sieved fraction. (A) Negative grains and (B) positive grains are aggregates of smectite and silicate minerals, apparently flocked during sieving. Arrows indicate micas.

relatively small quantities of nonexpansible phyllosilicates could predominate in determining sediment ${ }^{137} \mathrm{Cs}^{+}$activities. In separate research (27), the sorption and desorption of $\mathrm{Cs}^{+}$ on uncontaminated sediments from this stratum were described by a multisite model including a high-affinity site analogous to FES on micas. The coarse fraction $(>0.25 \mathrm{~mm})$ contained abundant large flakes of mica, along with primary silicates, such as quartz and feldspar. The latter would not be expected to significantly sorb ${ }^{137} \mathrm{Cs}^{+}$. The intermediate fractions $(0.053-0.106 \mathrm{~mm})$ consistently showed lower unitmass activities than the bracketing coarse and fine sizes ( $>0.25$ and $<0.053 \mathrm{~mm}$; Tables $1-3)$. The inclusion of relatively less of the micaceous component and of little siltclay component in these intermediate size ranges could explain their relatively low unit-mass activities. Micas may have mechanically weathered from relatively large flakes to produce $<53-\mu \mathrm{m}$ fragments, but few flakes of intermediate size. This explanation is admittedly ad hoc but is consistent with the observations. In the fine fraction $(<0.053 \mathrm{~mm})$, expansible phyllosilicates were abundant, and these were expected to contribute high concentrations of low-affinity sites for ${ }^{137} \mathrm{Cs}^{+}$adsorption. Micaceous minerals were ubiquitous components of this fraction also, and the unit-mass activity of ${ }^{137} \mathrm{Cs}$ for the $<0.053-\mathrm{mm}$ size fraction could have a significant contribution from mica-bound ${ }^{137} \mathrm{Cs}^{+}$. The sizefraction activity results are thus consistent with the selective binding of $\mathrm{Cs}^{+}$by nonexpansible phyllosilicates.
TABLE 4. Single-Grain Radioactivity Counting Results

$\begin{array}{ccccl}\text { size }(\mu \mathrm{m}) & \text { no. } & \text { PSL/min }^{a} & \text { Bq }^{b} & \text { Bq SD }^{a} \\ 500-250 & 101 & 0.027 & -c & - \\ & 102 & 0.014 & 0.018 & 0.005 \\ & 103 & - & 0.009 & 0.005 \\ & 104 & 0.035 & 0.064 & 0.006 \\ & 105 & 0.010 & 0.010 & 0.005 \\ 250-106 & 106 & 0.016 & 0.014 & 0.005 \\ & 101 & 0.036 & 0.044 & 0.005 \\ & 102 & - & -0.008 & \\ & 103 & 0.005 & -0.012 & \\ & 104 & 0.014 & - & \\ & 105 & 0.0037 & 0.007 & 0.005 \\ & 106 & 0.016 & 0.007 & 0.005 \\ & 101 & 0.021 & 0.014 & 0.005 \\ & 102 & 0.012 & 0.016 & 0.005 \\ & 103 & 0.026 & 0.032 & 0.006 \\ & 104 & 0.041 & 0.047 & 0.006 \\ & 105 & 0.024 & 0.020 & 0.005 \\ & 106 & 0.040 & - & \end{array}$

a PSL units are based on background subtracted integrated areas after $4320 \mathrm{~min}(3 \mathrm{~d}$ ) of exposure. Background intensities were 0.0324 \pm 0.0005 PSL min $^{-1}$ ( 21 measurements). ${ }^{b} \mathrm{~Bq}$ measurements are by low-level $\gamma$-counting with counting uncertainties at the $1 \sigma$ level. A measurement of activity against SRM 4215B gave $2065 \mathrm{~Bq} \pm 8$. ${ }^{c}$ Unmeasured quantities are indicated by - .

Radiological Screening and Analysis. The research consensus has been that the small fraction of highest energy sites on the frayed edges of micas most strongly retain $\mathrm{Cs}^{+}$. Numerous investigations have shown the micaceous sheet silicates to beimportant in cesium immobilization; however, the experiments using specimen substrates were not fieldbased, and field investigations have been hampered by the very small activities (below the detection limit) of ${ }^{137} \mathrm{Cs}^{+}$ presenton thesurface of individual mineral grains. Thestrong adsorption of $\mathrm{Cs}^{+}$by illite has been demonstrated experimentally $(6,8,14,28,29)$, and, thus micaceousminerals were inferred to be responsible for the retention of ${ }^{137} \mathrm{Cs}^{+}$in sediments where a fraction of the total ${ }^{137} \mathrm{Cs}^{+}$could not be desorbed $(5,30)$. Francis and Brinkley (31) used a density separation method to show the presence of mica at low concentration in a contaminated sediment and found that the mica-including density fractions were enriched in ${ }^{137} \mathrm{Cs}$, deductively demonstrating that micas were an important ${ }^{137} \mathrm{Cs}^{+}$-retaining phase. Our results confirm directly the importance of micas in binding ${ }^{137} \mathrm{Cs}^{+}$in contaminated sediments.

Digital phosphor-plateimages provided a means of rapid detection and identification of ${ }^{137} \mathrm{Cs}^{+}$-sorbing particles. Sediment clasts that showed positiveautoradiography results were morphologically and mineralogically distinct from negative clasts. In the fine and very fine sand fractions (53$250 \mu \mathrm{m}$ ), the positive clasts consisted of mineral fragments bound together by clay. As shown in Figure 3a, for the 53$106-\mu \mathrm{m}$ fraction, the negative clasts were predominantly particles of quartz and plagioclasefeldspar, with somesurface staining by fine iron oxide. The positive clasts, in contrast, were consistently larger than the maximum size nominally allowed by the sieving procedure: they were aggregates (Figure 3b). Close examination of the aggregates showed an abundance of mica. The grains in Figure $3 b$ have partially disaggregated during manipulation, revealing micas as either translucent large flakes or as small, dark constituent flakes at the surface of the clumped material. Examination of disaggregated positive grains using optical and electron microscopy showed them to consist of quartz and plagioclase as well as mica and smectite.

The single-grain exposure measurements from autoradiography images provided a numerical valuefor radioactivity 


\section{$\circ$

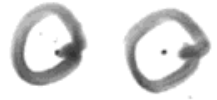 .}

106-250 black
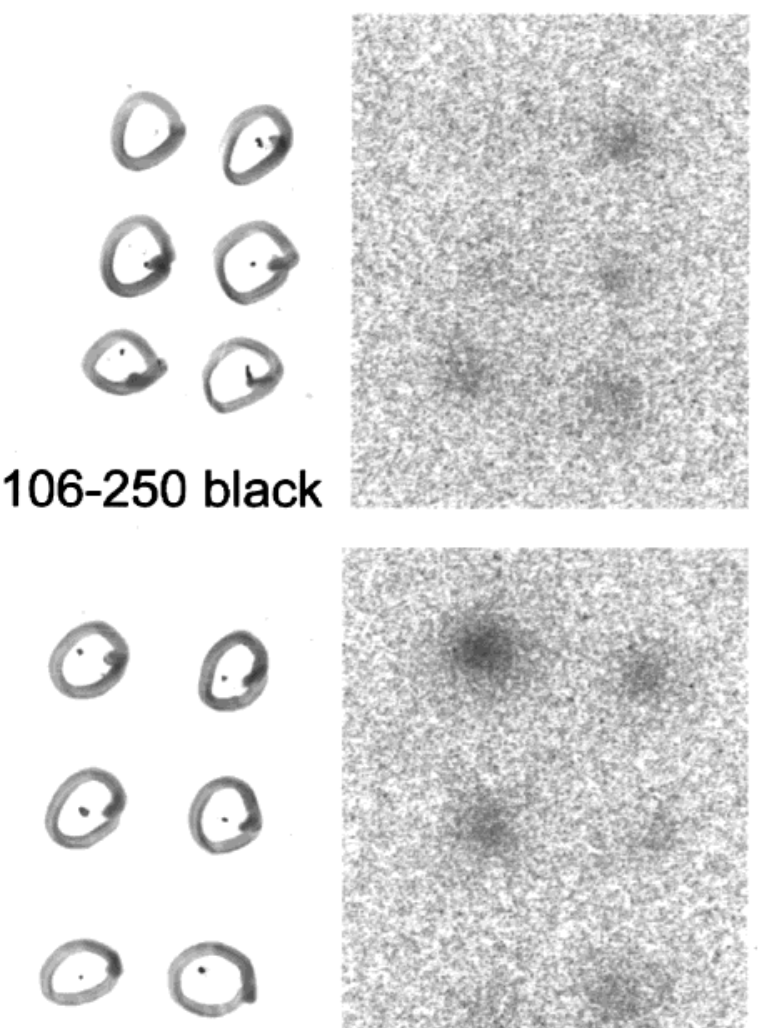

106-250 rust

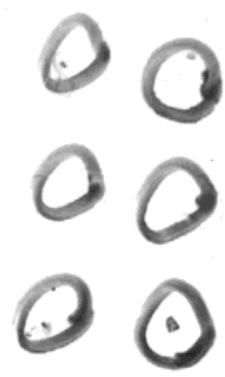

106-250 trans

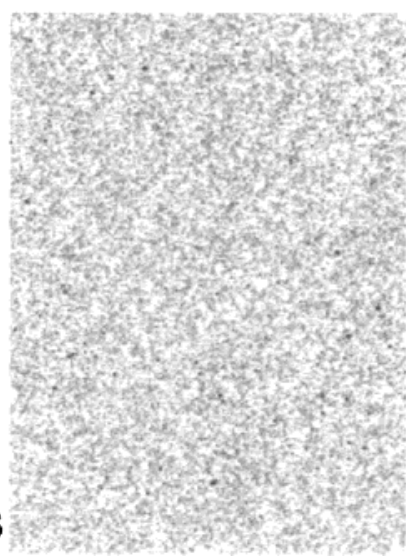

\section{. \\ (3) \\ . \\ 250-500 black}

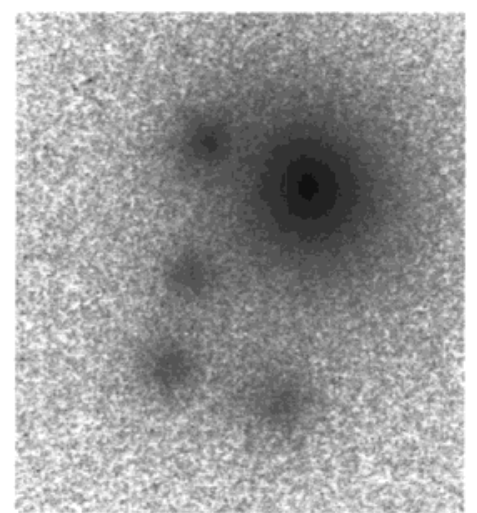

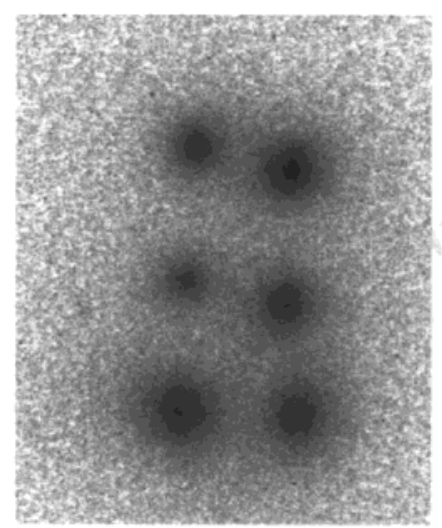

\section{$250-500$ rust}

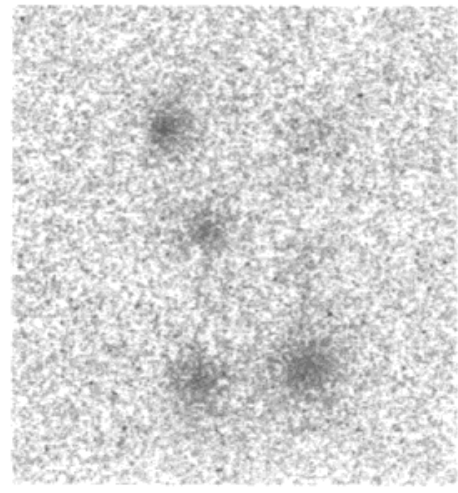

FIGURE 4. Digital autoradiographs and optical micrographs of mica flakes hand-picked from contaminated sediments. Size fractions are indicated in micrometers (e.g., 106-250 $\mu \mathrm{m}$ ). Mica phases w ere differentiated by color: black, biotite; rust, vermiculite; and trans(parent), muscovite. Each mica was mounted to the glass slide and circled on the underside using a marking pen.

(in units of PSL). These numerical results had good correspondence to $\gamma$-counting measurements $\left(r^{2}=0.83\right)$. PSL signals may have originated from ${ }^{137} \mathrm{Cs} \beta$ - or $\gamma$-radiation or both (32). $\gamma$-Counting at the appropriate energy confirmed ${ }^{137} \mathrm{Cs}$ as the radiation source. PSL measurements were more sensitive than $\gamma$-counting and thus could estimate ${ }^{137} \mathrm{Cs}$ activities that were detectable by the phosphor system when these same activity levels were too small to be detected by $\gamma$-spectrometry. This was utilized for particle 250-103 and improved the confidence in the uncertain $\gamma$-detection of particles 250-106 and 250-105 (Table 4).

The examination of positive clasts suggested that the selection of clasts for single-clast autoradiography and $\gamma$-counting might be biased toward agglomerated small particles, since the strongest radiological results would tend to comefrom relatively large aggregates of materials including numerous positive components. We determined the relative significance of different agglomeratecomponents by logically evaluating the autoradiography results and by performing additional autoradiography measurements. The primary silicates (quart and feldspar), incorporated in the agglomerates, could be ruled out as sources of radiation by analogy to negativeclasts. The retention of ${ }^{137} \mathrm{Cs}^{+}$by micas was tested directly by picking mica flakes from the $0.106-0.250$ - and $0.250-0.500-\mathrm{mm}$ size fractions (Figure 4). The micas were all confirmed to significantly retain ${ }^{137} \mathrm{Cs}^{+}$by producing positive autoradiographs. Biotite and vermiculite showed strongly positiveresults, with muscoviteretaining less ${ }^{137} \mathrm{Cs}^{+}$ than the other micas. During physical manipulation, "vermiculite" flakes often delaminated and were observed to consist of a rusty cover or sheath of vermiculite over a relatively pristine core of biotite; the retention of ${ }^{137} \mathrm{Cs}^{+}$ ascribed to vermiculite was therefore likely due to retention by biotiteor a composite of biotiteand vermiculite. Thethree micas in any case showed a higher affinity than other phases for ${ }^{137} \mathrm{Cs}^{+}$. In coarser fractions, only micaceous minerals were 
TABLE 5. Chemical Treatment and Desorption Results for Size Fractions of Sample $2 C / D^{a}$

\begin{tabular}{|c|c|c|c|c|c|c|c|c|}
\hline \multirow[b]{2}{*}{ treatment } & \multirow[b]{2}{*}{$\begin{array}{c}\text { sample } \\
(\mu \mathrm{m})\end{array}$} & \multicolumn{3}{|c|}{$\begin{array}{l}\text { chemical treatment results } \\
\text { (mean of duplicate) }\end{array}$} & \multicolumn{4}{|c|}{$\begin{array}{c}\text { Rb desorption results } \\
\text { (triplicate) } \\
\%{ }^{137} \text { Cs removed }\end{array}$} \\
\hline & & $\begin{array}{c}\mathrm{Fe} \\
\text { dissolved }^{b}\end{array}$ & $\begin{array}{l}\text { sediment } \\
\text { dissolved }^{b}\end{array}$ & $\begin{array}{l}\%{ }^{137} \mathrm{Cs} \\
\text { removed }\end{array}$ & $\begin{array}{l}1 \mathrm{~d} \\
\text { mean }\end{array}$ & $1 \sigma$ & $\begin{array}{l}29 \mathrm{~d} \\
\text { mean }\end{array}$ & $1 \sigma$ \\
\hline \multirow[t]{3}{*}{ dithionite } & bulk & 1.3 & 5 & 5.6 & 6 & 2 & 14 & 2 \\
\hline & $250-106$ & - & - & 7.8 & 6 & 3 & 20 & 2 \\
\hline & $<53$ & 0.80 & 7 & 5.2 & 10 & 2 & 21 & 4 \\
\hline \multirow[t]{3}{*}{ Tamm's } & bulk & 0.44 & 3 & 5.3 & 3 & 1 & 8 & 0 \\
\hline & $250-106$ & - & - & 7.5 & 7 & 1 & 22 & 4 \\
\hline & $<53$ & 0.66 & 6 & 5.0 & 8 & 1 & 19 & 5 \\
\hline \multirow[t]{3}{*}{$\mathrm{KOH}$} & bulk & $\mathrm{bd}$ & 1 & 1.8 & 4 & 1 & 10 & 1 \\
\hline & $250-106$ & bd & - & 2.3 & 13 & 7 & 22 & 1 \\
\hline & $<53$ & bd & 2 & 2.3 & 4 & 2 & 14 & 1 \\
\hline \multirow[t]{3}{*}{$\mathrm{HNO}_{3}$} & bulk & 2.3 & 9 & 23.3 & - & & - & \\
\hline & $250-106$ & - & - & 16.7 & - & & - & \\
\hline & $<53$ & 1.0 & 26 & 16.0 & - & & - & \\
\hline untreated & bulk & - & - & - & 3 & 1 & 5 & 2 \\
\hline
\end{tabular}

present to sorb ${ }^{137} \mathrm{Cs}^{+}$. In finer fractions, smectite was also present and could sorb ${ }^{137} \mathrm{Cs}^{+}$, but the waste solutions that bore ${ }^{137} \mathrm{Cs}^{+}$were high in $\mathrm{Na}^{+}$, which suppresses $\mathrm{Cs}^{+}$adsorption to low-affinity sites on smectites. The other mineral phases, primary silicates, do not significantly retain $\mathrm{Cs}^{+}$. The observation that coarse fractions sorb ${ }^{137} \mathrm{Cs}^{+}$disproportionate to their abundance and the presence of micaceous minerals in thosefractions as the only ${ }^{137} \mathrm{Cs}^{+}$-retaining phase, suggested that micas are the predominant control of $\mathrm{Cs}^{+}$mobility in these sediments.

Chemical Treatment and Desorption Experiments. The ${ }^{137} \mathrm{CS}^{+}$-containing waste solutions were hot and contained high base $\left(\mathrm{OH}^{-}\right)$and aluminate $\left[\mathrm{Al}(\mathrm{OH})_{4}^{-}\right]$, which may have induced the dissolution of phyllosilicates containing oxidizable $\mathrm{Fe}(\mathrm{II})$ and the precipitation of secondary phases including ferric oxyhydroxides and aluminum oxide. Our dissolution/ desorption experiments suggested that secondary phases affected the desorption of ${ }^{137} \mathrm{Cs}^{+}$(Table 5). The untreated bulk sediment released only $5 \%$ of thetotal sorbed ${ }^{137} \mathrm{Cs}^{+}$when reacted with $\mathrm{Rb}^{+}$for 29 days (Table 5 ). The use of chemical pretreatments increased the release of sorbed ${ }^{137} \mathrm{Cs}^{+}$. The precipitation of secondary phases, either directly from waste solutions or after reaction with the sediment, may have blocked surface sorption sites, which were accessible to $\mathrm{Rb}^{+}$after their dissolution. Since nitric acid could both dissolve secondary phases and desorb ${ }^{137} \mathrm{Cs}^{+}$by exchange with $\mathrm{H}^{+}$, treatment with nitric acid alone was equivalent in some ways to dissolution/desorption. Nitric acid dissolved a significant percentage of the reacted sediment and removed ${ }^{137} \mathrm{Cs}^{+}$that approximately equaled the amount removed by the other treatments. Pretreatment with iron-extracting (dithioniteand Tamm's) and aluminumextracting $(\mathrm{KOH})$ solutions caused a marked increase in ${ }^{137} \mathrm{Cs}^{+}$ desorption to $15-30 \%$ of thetotal. In thethree pretreatments, the fractions of ${ }^{137} \mathrm{Cs}^{+}$removed by exchange with $\mathrm{Rb}^{+}$for 29 days were approximately equivalent. These results were consistent with the formation of an armor of secondary precipitates of iron or aluminum oxide on the surfaces of sorbing solids that prevented exchange of ${ }^{137} \mathrm{Cs}^{+}$with the aqueous phase; ${ }^{137} \mathrm{Cs}^{+}$desorption from interlaminar wedge or planar sites on the sorbing phyllosilicates followed the dissolution of these phases by pretreatment.

An alternative explanation is suggested by the extent of ${ }^{137} \mathrm{Cs}^{+}$extraction prior to desorption, and other extraction data included in Table 5. Data are few, i.e., four points, but within a given size fraction there is a strong correlation between the fraction of sediment dissolved and the ${ }^{137} \mathrm{Cs}^{+}$ removed during chemical treatment (the correlation of wt $\%$ sediment dissolved to $\%{ }^{137} \mathrm{Cs}^{+}$removed was $\mathrm{r}^{2}=0.88$ for bulk sediment and $r^{2}=1.00$ for the $<53-\mu \mathrm{m}$ fraction). The ${ }^{137} \mathrm{CS}^{+}$may have been removed from $\mathrm{FES}$ by reaction dissolution of the mica edges with the pretreatment agents. The ${ }^{137} \mathrm{Cs}^{+}$freed by dissolution (or by desorption by the K or $\mathrm{NH}_{4}{ }^{+}$component of the pretreatment) would then have resorbed to available surface sites. Desorption with $\mathrm{Rb}^{+}$ immediately following extraction could then have removed the resorbed ${ }^{137} \mathrm{Cs}^{+}$, contributing to the apparent large increase in desorbable ${ }^{137} \mathrm{Cs}^{+}$seen in Table 5. The ${ }^{137} \mathrm{Cs}^{+}$ liberated to solution by pretreatment would only have been sorbed for a short period before desorption with $\mathrm{Rb}^{+}$. Although binding of $\mathrm{Cs}^{+}$to surface sites on micas may be strong and selective, desorption soon after binding is more effective than desorption after the passage of time $(5,6)$. The time dependence of ${ }^{137} \mathrm{Cs}^{+}$desorption over $1-29$ days may thus result from the inverse of slow-binding kinetics for fixation to selective sites (8). This explanation is supported indirectly by dissolution data (Table 5); while the amount of iron dissolved by iron-extracting reagents amounted to about one-half to a little more than 1 wt \%, the percent of bulk sediment dissolved was 3-7 wt \%. Reaction with $\mathrm{KOH}$ dissolved 1-2 wt \% of the sediment. Either type of reagent (iron-reducing or alumina-dissolving) could have attacked the weathered FESon iron-bearing silicates, destroying them and removing the ${ }^{137} \mathrm{Cs}^{+}$bound to them. TheFES were present in gross overabundance to ${ }^{137} \mathrm{CS}^{+}$and also could have been recreated at chemically reacted mineral surfaces, providing sites for the readsorption of liberated ${ }^{137} \mathrm{Cs}^{+}$.

At most, less than $30 \%$ of the available ${ }^{137} \mathrm{Cs}^{+}$was removed by pretreatment and desorption with $\mathrm{Rb}^{+} .{ }^{137} \mathrm{Cs}^{+}$in contact with FES for $30 \mathrm{yr}$ may have participated in ongoing exchange with interlayer $\mathrm{K}^{+}$, and thesesites may have been less reacted than FES during pretreatment. Also, only a fraction of the ${ }^{137} \mathrm{CS}^{+}$-binding FES may have been altered by pretreatment solutions, leaving a significant fraction of the sorbed ${ }^{137} \mathrm{Cs}^{+}$ on mineral surfaces.

Long-Term Retention of Cs. Thecombination of sediment characterization with the chemical treatment and subsequent desorption of ${ }^{137} \mathrm{Cs}^{+}$provides data that can be integrated to provide information on the retention of Cs leaked from $\mathrm{HLW}$ waste-storage tanks.

The chemical leaching of sediments by chemical reagents suggested that some iron oxide minerals were present. Dithionite and Tamm's reagent removed 28 and $9 \%$ of the sediment total iron, respectively (Table 5), whereas treatment 
of the bulk sample with nitric acid removed $48 \%$ of the total Fe. The presence of iron oxyhydroxides does not suggest that they contributed to ${ }^{137} \mathrm{Cs}$ immobilization. It is unlikely that the adsorption of ${ }^{137} \mathrm{Cs}^{+}$to iron (or aluminum) oxides contributed to immobilization since $\mathrm{Cs}^{+}$is weakly and nonspecifically sorbed by oxides of Fe, $\mathrm{Mn}$, and $\mathrm{Al}$ (33-38). Excess concentrations of other monovalent cations (e.g., $\mathrm{Na}^{+}$) virtually eliminate $\mathrm{Cs}^{+}$adsorption to metal oxides through competitive mass action (39).

The silicate minerals other than the phyllosilicates can be dismissed as significant contributors to $\mathrm{Cs}^{+}$retention. While the surfaces of grains of the primary silicates (quartz, feldspar, etc.) can be conceptualized to possess chemically altered surfaces capable of sorbing $\mathrm{Cs}^{+}$(e.g., smectite-like surfaces), our data do not identify any significant sorption of ${ }^{137}$ Cs to silicate clasts. All positive digital autoradiography images were associated with clasts containing mica, and all negative clasts were primary silicates (quartz and feldspar).

The remaining ${ }^{137} \mathrm{Cs}$-associated phases were either specifically identified to be micas or were multi-mineral clasts including micas and expansible layer silicates. The XRD analysis of theclay-sized fraction included kaolinite, smectite, plagioclase, and quartz along with mica.

The potentially significant sorbers for $\mathrm{Cs}^{+}$fall into two components with differing properties: strongly sorbing nonexpansible phyllosilicates (micas) with relatively low cation-exchange capacity (CEC) and more weakly sorbing expansible phyllosilicate clay minerals with relatively high CEC. Cesium has been widely observed to be strongly and selectively adsorbed by micaceous minerals in soils and sediments $(7,26,29,31)$. It is also readily adsorbed by other phyllosilicates where its behavior is similar to other cations (15) and less selectively and strongly bound than on micas. The sediment system may thus be considered to consist functionally of a set of strong and weak binding sites with the strong sites preferentially binding $\mathrm{Cs}^{+}$until they are at or near saturation, followed by $\mathrm{Cs}^{+}$binding to weaker sites. These observations have been made for other mineral and sediment systems $(5,9)$ and have led to the application of multisite models to describe $\mathrm{Cs}^{+}$sorption (40-43).

In sediments contaminated $30 \mathrm{yr}$ ago with tank-derived HLW, the majority of ${ }^{137} \mathrm{Cs}^{+}$was apparently strongly bound to FES. Our extraction and desorption results suggested that approximately $70-80 \%$ of the sorbed ${ }^{137} \mathrm{Cs}^{+}$(i.e., the fraction not exchangeable with $\mathrm{Rb}^{+}$) was bound by these sites and does not present much concern for future mobilization by less reactive fluids. Some of the sorbed ${ }^{137} \mathrm{Cs}^{+}$in the contaminated sediments may have been bound to phyllosilicate clay minerals. The quantity of ${ }^{137} \mathrm{Cs}^{+}$sorbed to expansible phyllosilicate clays could be readily mobilized by exchange with other cations and could migrate with desorbing solutions. Careful experimental evaluation of the partitioning of ${ }^{137} \mathrm{Cs}^{+}$to micas and clays and of the potential effects of high concentrations of competing cations must be completed before conclusions are drawn regarding the mobility of desorbable ${ }^{137} \mathrm{Cs}^{+}$. However, uncontaminated micas downgradient from the point of desorption in vadose subsurface sediments would strongly retard future ${ }^{137} \mathrm{Cs}^{+}$ migration, limiting potential breakthrough to groundwater.

Theultimate ${ }^{137} \mathrm{Cs}^{+}$concentration in these sediments was very low (ca. $1.0 \times 10^{-11} \mathrm{~mol} / \mathrm{g}$ ). In a related paper (27), we have comprehensively studied $\mathrm{Cs}^{+}$adsorption to a pristine analogue of thecontaminated material studied here. Through a multisite modeling approach, we estimated that the total concentration of high-affinity FES sites in the bulk sediment was quite low (e.g., $3.45 \times 10^{-8} \mathrm{~mol}$ equiv/ g or $0.08 \%$ of the total CEC). Despite the paucity of high-energy sites, thetotal ${ }^{137} \mathrm{Cs}^{+}$in the contaminated sediment could be bound by only $0.008 \%$ of them. Even if the total $\mathrm{Cs}^{+}$concentration was taken to be about five times the ${ }^{137} \mathrm{Cs}^{+}$concentration $\left({ }^{137} \mathrm{Cs}^{+}\right.$was ca. $20 \%$ of the total $\mathrm{Cs}^{+}$extracted after cation exchange for 31 days; data not shown), the total exchangeable $\mathrm{Cs}^{+}$would amount to a tiny fraction of the high-energy sites. Thus, the high-energy sites on micas are abundant, and partitioning to the expansible phyllosilicates seems unlikely.

\section{Acknowledgments}

We would like to thank two anonymous reviewers whose detailed comprehensive comments greatly improved the manuscript. This work was supported in part by the U.S. Department of Energy, Office of Science and Office of Environmental Management, Environmental Management Science Program. Pacific Northwest National Laboratory is operated by Battelle Memorial Institute for the U.S. Department of Energy. Certain commercial equipment, instruments, or materials areidentified to specify experimental procedures. Such identification does not imply recommendation or endorsement by the National Institute of Standards and Technology or the Pacific Northwest National Laboratory.

\section{Literature Cited}

(1) Tallman, A. M.; Fecht, K. R.; Marratt, M. C.; Last, G. V. Geology of the Separations Areas, Hanford Site, South-Central Washington; Report RHO-ST-23; Rockwell Hanford Operations: Richland, WA, 1979

(2) Freeman-Pollard, J. R.; Caggiano, J. A.; Trent, S. J. Engineering Evaluation of the GAO/RCED-89-157, Tank 241-T-106 Vadose Zone Investigation; Report BHI-00061; Bechtel Hanford, Inc.: Richland, WA, 1994.

(3) Parkhurst, D. L.; Appelo, C. A. J. User's Guide to PHREEQC (Version 2)-A computer Program for Speciation, Batch-Reaction, One-Dimensional Trahsport, and Inverse Geochemical Calculations; U.S. Geological Survey: Denver, CO, 1999.

(4) Cornell, R. M. J. Radioanal. Nucl. Chem. 1993, 171, 483.

(5) Evans, D. W.; Alberts, J. J.; Roy A.; I. C. Geochim. Cosmochim. Acta 1983, 47, 1041.

(6) Comans, R. N. J.; Hockley, D. E. Geochim. Cosmochim. Acta 1992, 56, 1157.

(7) Sawhney, B. L. Clays Clay Miner. 1970, 18, 47.

(8) Comans, R. N.J.; Haller, M.; dePtreter, P. Geochim. Cosmochim. Acta 1991, 55, 433.

(9) Francis, C. W.; Brinkley, F. S. Nature 1976, 260, 511.

(10) Smith, J. T.; Comans, R. N. J.Geochim. Cosmochim. Acta 1996, 60, 995.

(11) ASTM. Method D422-63; American Society for Testing and Materials: West Conshohoken, PA, 1998.

(12) Loeppert, R. H.; Inskeep, W. P. In Methods of Soil Analysis, Part 3. Chemical Methods; Sparks, D. L., Ed.; Soil Science Society of America: Madison, WI, 1996.

(13) Holmgren, G. G.; Kimble, J. M. Soil Sci. Soc. Am. J. 1984, 48, 1378.

(14) Brouwer, E.; Baeyens, B.; Cremers, A. J. Phys. Chem. 1983, 87, 1213.

(15) Sposito, G. TheChemistry of Soils; Oxford University Press: New York, 1989.

(16) Betti, M.; Tamborini, G.; Koch, L. Anal. Chem. 1999, 71, 2616.

(17) Saari, H.; Luokkanen, S.; Kulmala, M.; Lehtinen, S.; Raunemaa, T. Health Phys. 1989, 57, 975.

(18) Zeissler, C. J.; Wight, S. A.; Lindstrom, R. M. Appl. Radiat. Isot. 1998, 49, 9.

(19) Zeissler, C. J.; Lindstrom, R. M.; McKinley, J. P. J. Radioanal. Nuclear Chem. 2001, 48, 407.

(20) Taylor, B. N.; Kuyatt, C. E. Guidelines for Evaluating and Expressing the Uncertainty of NIST Measurement Results; NIST Technical Note 1297; National Institute of Standards and Technology: Gaithersberg, MD, 1993.

(21) Miyahara, J. Chem. Today (Tokyo) 1989, 223, 29.

(22) Lindstrom, R. M.; Lindstrom, D. J.; Slaback, L. A.; Langland, J. K.: Nuclear Instrum. Methods Phys. Res. 1990, A299, 425.

(23) Lindstrom, R. M. Biol. Trace Element Res. 1994, 43-45, 597.

(24) Currie, L. A. Anal. Chem. 1968, 40, 586.

(25) McKinley, J.; Zachara, J. M.; Fredrickson, J. K.; Stevens, T. O.; Kieft, T. L.; Balkwill, D. L.; Ghiorse, W. C.; Rawson, S. A.; Long, P. E. Proceedings of the 2nd International Symposium on Subsurface Microbiology, Bath, U.K., 1993.

(26) Sawhney, B. L. Clays Clay Miner. 1972, 20, 93.

(27) Zachara, J. M.; Smith, S. C.; Serne, R. J.; McKinley, J. P.; Gassman, P. Geochim. Cosmochim. Acta, in press. 
(28) Poinssot, C.; Baeyens, B.; Bradbury, M. H. Geochim. Cosmochim. Acta 1999, 63, 3217.

(29) Tamura, T.; Jacobs, D. G. Health Phys. 1960, 2, 391.

(30) Grutter, A.; Gunten, H. R. v.; Rossler, E.; Keil, R. Radiochim. Acta 1994, 64, 247.

(31) Francis, C. W.; Brinkley, F. S. Nature 1976, 260, 511.

(32) Lederer, C. M.; Shirley, V. S.; Browne, E.; Dairiki, J. M.; Doebler, R. E.; Shihab-Elden, A. A.; Jardine, L. J.; Tuli, J. K.; Buyrn, A. B. Table of Isotopes, 7th ed.; John Wiley \& Sons: New York, 1978.

(33) Helferrich, F. Ion Exchange; McGraw-Hill Book Co.: New York, 1962.

(34) Tien, H. T. J. Phys. Chem. 1965, 69, 350

(35) Churms, S. C. J. S. Afr. Chem. Inst. 1966, 19, 98.

(36) Abendroth, R. P. J. Colloid Interface Sci. 1970, 34, 591.

(37) Breuwsma, A.; Lyklema, J. Discuss. Faraday Soc. 1971, 52, 324.

(38) Venkataramani, B.; Venkateswarlu, K. S.; Shankar, J. J. Colloid Interface Sci. 1978, 67, 187.
(39) Kinniburgh, D. G.; Jackson, M. L. In Adsorption of Inorganicsat Solid-Liquid Interfaces; Anderson, M. A., Rubin, A. .., Eds.; Ann Arbor Science Publishers: Ann Arbor, MI, 1981.

(40) Wauters, J.; Elsen, A.; Cremers, A.; Konoplev, A. V.; Bulgakov, A. A.; Comans, R. N. J. Appl. Geochem. 1996, 11, 589.

(41) Wauters, J.; Vidal, M.; Elsen, A.; Cremers, A. Appl. Geochem. 1996, 11, 595.

(42) Wauters, J.; Elsen, A.; Cremers, A. Appl. Geochem. 1996, 11, 601.

(43) De Preter, P.; Van Loon, L.; Maes, A.; Cremers, A. Radiochim. Acta 1991, 52/53, 299.

Received for review October 26, 2000. Revised manuscript received May 15, 2001. Accepted May 22, 2001.

ES0018116 